\title{
Public-private partnership in health care organizations. How to cope with complexity issues: a comparative case-study between Italy and the US
}

\author{
Lorenzo Pratici
}

Department of Economics and Management, Università degli Studi di Parma, Parma, Italy, and

Phillip McMinn Singer

University of Utah Health, Salt Lake City, Utah, USA

\begin{abstract}
Purpose - Health-care systems around the globe share several pressing challenges - including increasing costs and patient outcomes. Innovative arrangements, such as public-private partnerships (PPP) can be adopted to help address these challenges. Although the promise of PPPs is great, so are its peril if the arrangements are not managed and regulated adequately through the contracting process. Yet, PPP arrangements can introduce their own unique set of problems. This paper aims to analyze how PPPs contracting accounts for three major problems identified reviewing the: performance measurement and audit; determination of compensation and risk management-related issues.

Design/methodology/approach - The authors used a case study approach to analyze contracting among health-care PPPs in two countries: Italy and the USA. With a structured review performed on Scopus database using a keywords Boolean research, the authors identified three recurring major issues to investigate in two selected cases, one per country. For each major issue, the authors defined several sub-issues retrieved from a widely used institutional framework. In each sub-issue, a documental analysis on all published information related to the signed contract has been performed identifying the approaches used by the two organizations.

Findings - The authors find that PPP contracting in the USA case seems to be oriented more toward managing institutional change as well as more flexibility in the deductibility and compensation determination for organizations and providers, suggesting this organization is more oriented to change in general. The authors find that PPP contracting in Italy more clearly delineate the allocation of risk between organizations that engage in PPPs, suggesting a more practical approach.

Practical implications - PPP is complex. Contracting helps manage the complexity of these arrangements. This case study approach to PPP contracting highlights the variation in contracting approaches across two different countries. Policymakers and health-care managers need to ensure that PPP contracting clearly delineates auditing and performance measurement, compensation and risk management.
\end{abstract}

(C) Lorenzo Pratici and Phillip McMinn Singer. Published by Emerald Publishing Limited. This article is published under the Creative Commons Attribution (CC BY 4.0) licence. Anyone may reproduce, distribute, translate and create derivative works of this article (for both commercial and noncommercial purposes), subject to full attribution to the original publication and authors. The full terms of this licence may be seen at http://creativecommons.org/licences/by/4.0/legalcode

This study has not been funded by any institution or organization.

There are no conflicts of interest referred to this study.
Received 30 July 2020 Revised 21 December 2020

10 February 2021 2 March 2021

Accepted 3 March 2021

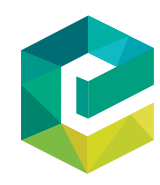

International Journal of Organizational Analysis Vol. 29 No. 6 . 2021 l. 29 No. 6,2021 pp. 1467-1482
Emerald Publishing Limited 1934-8835 
IJOA

29,6

Originality/value - The authors' analysis sheds light on the different approaches to arranging health-care PPPs in two different country settings. More research should be done to connect these different approaches to important outcomes, such as patient and organizational finances, as well as expanding the scope of countries adopting PPP in health care.

Keywords PPP, Health care, United States, Italy, Risk allocation, Performance measurement and auditing, Determination of compensation, Complexity, Compensation determination

Paper type Research paper

\section{Introduction}

Health-care systems around the globe face cost and quality pressure. Health-care systems and policymakers have several options at their disposal to address these challenges - including privatization. Nearly all health-care systems involve a mixture of public and private providers (Brekke and Sørgard, 2007). In countries with National Health Service (NHS) systems, in which health care is generally financed by general taxation revenues (Propper, 2000), the private sector still exists alongside the public. Indeed, in NHS systems, the role of the private sector represents a growing phenomenon (Brekke and Sørgard, 2007; Propper, 2000), particularly as governments grapple with rising costs and limited resources (Mehl et al., 2014), as well as public demand for improved quality of care (Goh and Marimuthu, 2016).

Yet, privatization is not without risks and can lead to a variety of suboptimal consequences (Duggan et al., 2015), including drifting from the core tenets of the public health sector system and raise concerns over equity (Thomson and Mossialos, 2006). Indeed, the issue of equity is often contested in NHS countries where the wealthy can purchase private insurance that supplies access to more timely care, more robust benefit plans, higher quality providers (Del Vecchio et al., 2015; Hullegie and Klein, 2010) and private facilities (Herr et al., 2011; Tiemann and Schreyögg, 2009).

One potential arrangement to manage these competing challenges is public-private partnership (PPP). Although the promise of PPPs is great, so are its peril if the arrangements are not managed and regulated adequately, through the contracting process. Managing the competing and complementary aspects of public and private organizations has generated well-established literature (Propper, 2000; Meleddu et al., 2019). Policymakers need to balance the conflicting needs of reducing financial responsibilities for the state, improving the efficiency of privatization, all while ensuring the principles of equity. To manage these competing challenges, contracting is an essential process, though it has been understudied.

In this article, we analyze how two health-care organizations account for three central problems, which can undermine the effectiveness of the PPP arrangement. We use case studies and textual analysis of contract sources as well as other officially published agreements to understand whether and how PPP arrangements vary across health-care organizations in the USA and Italy and how they address the main issues occurring in a PPP contract.

\section{Problems with public-private partnerships. How to cope with complexity}

PPP is conceptually any arrangement between public and private entities in a given domain. Several academic disciplines have conceptualized and studied PPP, including organizational economics, public administration and project management (Hodge and Greve, 2017). For example, scholars of managerial studies (Bovaird, 2007; Brinkerhoff and Brinkerhoff, 2011; Osbourne, 2000; Torchia and Calabrò, 2018) proposed an inclusive definition of PPPs, arising from the New Public Management approach. The use of PPP in our analysis follows from Kivleniece and Quelin (2012, p. 273), which classifies PPPs as a project-based organization involving collaborators from the public and the private sector in a long-term 
collaborative relationship - at least 10 years - between one or more firms and public bodies that combine public sector management.

Considering the length of the time frame, as well as the collaboration between two entities with very different structures and scopes, PPPs are subject to a complex framework of laws and regulations (Kivleniece and Quelin, 2012; Torchia and Calabrò, 2018; Shrestha et al., 2019). Prior research highlights the potential problems in the use of PPPs. Torchia and Calabrò (2018) argue that measuring and auditing PPPs performances is challenging. Kivleniece and Quelin (2012) focus on the problem of risk allocation, which sometimes represents a strong barrier for issues this market. Shrestha et al. (2019) argues that the effectiveness of PPPs can be limited by principal-agent theory the importance of the determination of compensation. Robinson and Scott (2009) included in their work the sum of these challenges to be faced by PPPs.

So, although essential to the success of a PPP arrangement, contracting is a complex and an overlooked aspect of prior research. In this paper, we address three potential problems that can impair the PPP process and the ways which contracting in the USA and Italy do, or do not, address these complications. We selected two cases which have different political, social, regulatory and policy contexts to help understand different PPP approaches in health care. In the methodology section, we better explain how those issues have been selected.

\section{Performance measurement and auditing}

One of the key arguments for the adoption of PPP in health care is the demand for higher quality of care (Du Toit, 2003; Robinson and Scott, 2009). Developing a robust and effective performance measurement and audit system is complementary to this objective and has been associated with higher efficiency and positive outcomes (Partnership UK, 2006). For PPP arrangements, this is a crucial issue, as the private performer can have different objectives, such as profit generation (Ke et al., 2011). Therefore, it is essential that the public component of the PPP is able to audit and identify problems that may emerge through the PPP arrangement. At the same time, the private contractor has to be able to measure the performance to check on the economic sustainability of the undergoing activity.

\section{Determination of compensation}

PPPs can be costly arrangements. Both the public and private organizations take on financial risk. PPPs have many moving parts, with different organizations coming together in unique ways. This risk is heightened by having different stakeholders that do not all share the same goals. For example, the private entity seeks to maximize their profit, potentially at the expense of quality. The public organization, on the other hand, has asymmetrical information about the financial health of their organization. PPPs are typically structured to have private entities bear financial risk and setting remuneration linked to the achievement of predetermined performance standards (An et al., 2018). Determining compensation needs to occur at two levels when constructing PPP relationships. First, contracts need to delineate how the separate organizations share financial resources (Garen, 1994). Second, compensation needs to be delineated at the staff and provider level (Klingour et al., 2015). In both cases, PPP contracting needs to clearly explicate the payment mechanisms and performance metrics for the different organizations and staff in a PPP.

\section{Risk management-related issues}

PPPs are practical tools used by the public sector, among other things, to transfer a part of the whole risk to another entity. This type of contract often seeks to combine the advantages of competitive tender and flexible negotiation with a general reduction of risk for the public sector (Bing et al., 2005). 
IJOA

29,6

Transparency is critical for the success of a PPP (Jefferies et al., 2002; Shrestha et al., 2017); it is important that risk allocation is clearly communicated and understood by both parties (Bing et al., 2005). However, this often creates complexity in managing a PPP. Therefore, it is essential to clearly identify the risks that are shared and taken on by each component of a PPP. A strong and consolidated contractual structure prevents mismanagement of risk. The risk identification process then becomes important to avoid possible litigations during the contract implementation. Prior literature has proposed different methods of risk identification, but there is a widespread consensus on the checklist methodology as a frequently used framework (Italian Ministry of Economy, 2017).

\section{Method}

To analyze how health-care organizations manage the problems of PPPs, we use a comparative case study approach. We adopted the method proposed by Villani et al. (2017), identifying single areas of analysis for a documental study of available sources (contracts and published agreements in our case), using the framework identified by Robinson and Scott (2009).

To identify the areas of complexity, which we outlined above, we conducted a literature review. Using the Scopus database, with more than 20,000 peer-reviewed scientific journals listed (Brown, 2020; Fanelli et al., 2020; Mishra et al., 2017), we collected related literature. We conducted a Boolean research based on keywords: "Public Private Partnership" OR "PPP" AND Healthcare* OR "Health Care" OR "Hospitals." To identify the area of major concerns, we defined what were the most recurrent keywords present in the literature, excluding keywords on non-related issues (e.g. name of countries, the same keywords used in the Boolean research process, fields of research, such as "Health Policy" or "Economics" and strictly medical-related issues). We also excluded all papers not listed as "Business Administration," "Management," "Economics" and "Political Science" related. We also excluded all the "grey literature," considering only indexed journals' publications (Fanelli et al., 2020). This lead to an overall output consisted in 151 papers from the year 1982 to the year 2019 (the year 2020 has been excluded because it would have created a bias, having the keyword "Covid-19" and other keywords related to the pandemic crisis as outliers).

The most recurrent keywords, given all the criteria above, have been "procurement" appearing six times; "risk management," appearing five times and "performance measurement" appearing four times. From the analysis of the paper, which included the most recurrent keywords, three main topics emerged:

(1) performance measurement;

(2) determination of compensation of contractors; and

(3) risk management-related issues.

In light of this, we compared this literature with a framework, supported also by institutional entities regulating PPPs internationally and focused the work on the three main issues identified. For each issue identified, several sub-issues emerged from the framework, and we relied on them to assess the organizations taken into analysis.

Our case selection methodology sought to maximize variation along several dimensions. We selected two countries - Italy and the USA - which met several key criteria. First, we wanted to maximize variation in the level of privatization in the health-care contexts. As discussed below, Italy adopted an NHS system more than 40 years ago, whereas the USA is largely privatized. Second, we wanted to analyze country settings which regulate health care in different ways. Italy is highly structured in regulations of health-care organizations, 
whereas the USA has minimal public oversight of health-care organizations. By looking at countries with different regulatory scope, we can help identify the benefits and drawbacks to these different approaches on how PPP arrangements address the core problems we outlined above. Third, we sought cases which were in different timelines of PPP development, to understand whether there had been changes in PPP arrangements over time. Finally, we sought to select countries that faced similar challenges, namely, quality and cost control, which would lead to the adoption of PPP arrangements. Both Italy and the USA have seen health-care costs increasing, whereas government financial support has been decreasing. Additionally, concern over the quality of care and outcomes has increased in both countries.

Once we selected the case countries of interest, we selected two health-care organizations to analyze how they address the core problems related to PPPs. Italy has proactively adopted PPPs in the health-care setting. In that country, we selected one of the firstgeneration PPP projects. The project selected is well representative of a complete PPP, managing the construction of the building as well as all the non-sanitary-related services. The USA has a much smaller footprint in the PPP market for health-care organizations. We assessed all PPP projects undertaken in the USA and selected the most typical example of PPP arrangements - which in this instance was a PPP project, which would require the private entity to maintain and manage a public health-care organization which was facing dire financial challenges. Table 1 represents the main characteristics of the selected cases.

Furthermore, the methodology of case studies has been selected, as it provides the possibility of an in-depth investigation (Feagin et al., 1991). PPPs are generally very complex contracts, hardly conformable. So, although our case study approach is not generalizable, it does allow greater detail and the identification and comparison of themes across the two case studies. Furthermore, an international comparative case study makes it possible to sketch the main differences arising from the two systems in which the analyzed cases are operating and the complexities which govern their use and operation (Tellis, 1997).

To compare how these health-care organizations address the core problems with PPP, the framework identified points out for the first two areas analyzed (audit and performance measurement and determination of compensation) a list of key issues. Analyzing available contracts as well as secondary document consisting in any officially published agreement between the two parties available on the organizations' websites, we analyze how the two organizations addressed those issues. Additionally, to improve the model identified by Robinson and Scott (2009), adapting it to the purpose of this work, we included aspects on risk allocation, found to strongly affect the complexity of PPPs relations. The institutional framework used has been retrieved by Italian Ministry of Economy (2017), which classified the risk allocation into different areas. This choice finds its roots in the fact that it seems to be the most complete institutional framework between the two countries, and it is based on previous literature (Bing et al., 2005; Xu et al., 2010; Carbonara et al., 2015). Additionally, the framework has been applied in a variety of different fields (statistics, epidemiology, administrative law, etc.).

Before we provide an overview of the main results of our case studies, we describe the characteristics of the countries in our case study.

\section{Public-private partnetship in different contexts}

The Italian context. The Italian NHS (I-NHS) in 2018 celebrated its 40th anniversary: it is one of the few countries in the world which is still providing Universal Health Coverage (Signorelli et al., 2020) and has been ranked by international organizations as one of the best 


\begin{tabular}{l} 
IJOA \\
29,6 \\
$\mathbf{1 4 7 2}$ \\
\hline
\end{tabular}

Table 1.

Descriptive information of the two hospitals analyzed

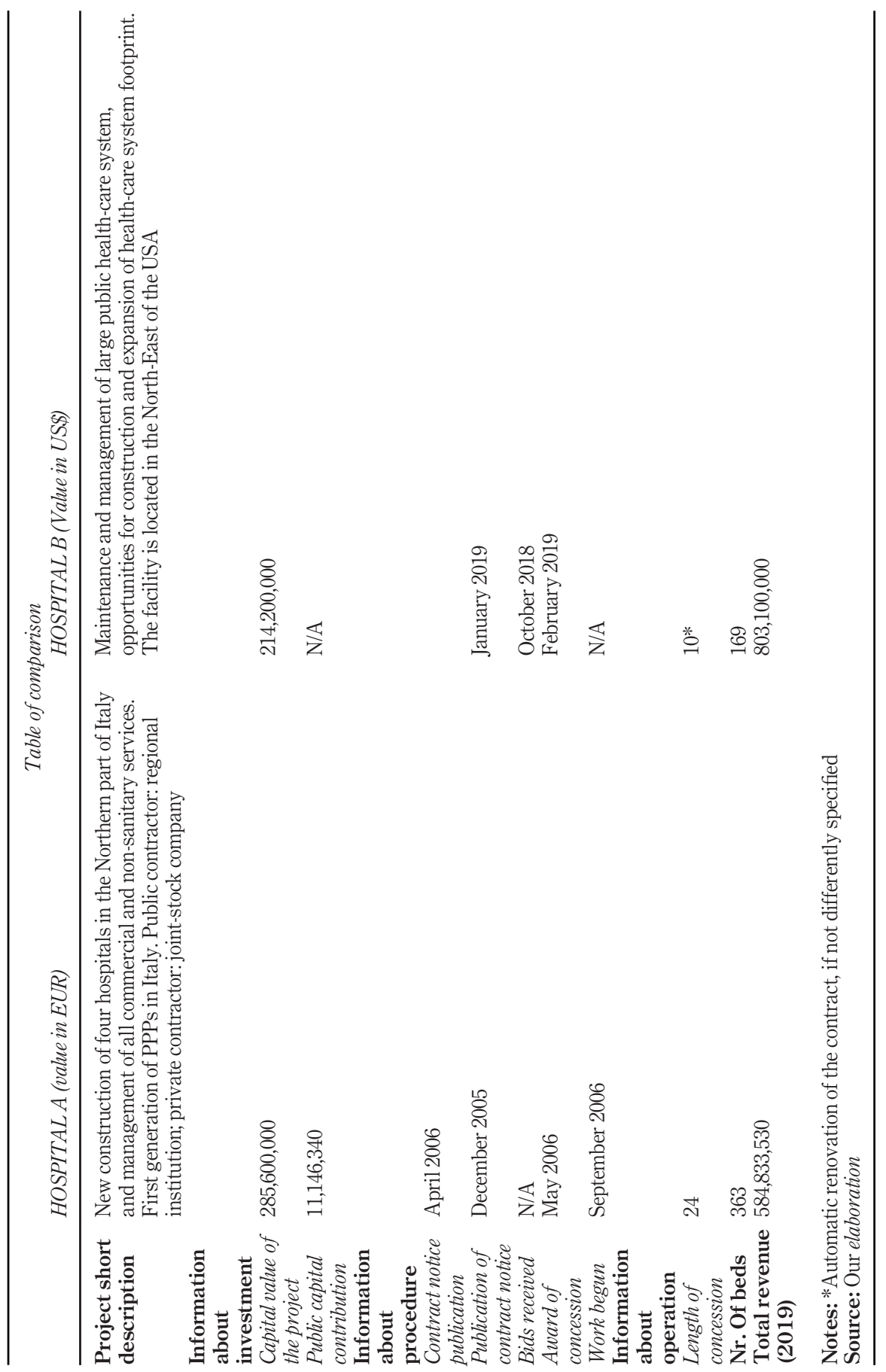


NHS systems worldwide (WHO, 2000, 2019). The I-NHS was founded with the guiding principles of universality, equity and solidarity (Signorelli et al., 2017).

Yet, in the wake of the 2008 financial crisis, the I-NHS had to make cuts to public health expenditure across each subsequent government (Ferrario and Zanardi, 2011; Neri, 2019) and raised concerns over the quality of care provided (Falco, 2019). Furthermore, the COVID-19 - currently ongoing - pandemics revealed the weaknesses of the system, suggesting potential issues to be faced (Fanelli et al., 2020). These stresses have provided an opening for greater involvement of the private sector (Torchia and Calabrò, 2018). issues Privatization concerns have forced the government to encourage and manage the formation of PPPs (Golinelli et al., 2017). The I-NHS, therefore, has developed the first PPP market inside the European Union (Osservatorio Finlombarda, 2011) and the second in Europe, after the UK (Torchia and Calabrò, 2018).

However, PPPs in Italy are often subject to a series of challenges. The general requirement for a PPP in Italy is to meet the principles expressed by the "Value for Money" theory. This theory evaluates costs and quality (Grimsey and Lewis, 2004) over different determinants (Torchia and Calabrò, 2018), including: risk allocation-related issues and auditing and performance measurement. Our case study will assess how the Italian healthcare organization dealt with those issues and how it contractually managed the intrinsic complexity of the PPP.

The USA context. The USA is the leading country in the volume of and the value of PPP projects globally, with more than $\$ 81$ bn in value over 326 PPP projects in 2018 . Yet, the health-care market for PPP is not as well developed as Italy, nor many other developed countries. The majority of PPP in the USA is focused on technology, energy and transport sectors, which have traditionally had sizeable public spending. Indeed, the roots of the PPP in the USA started several hundred years ago as a mechanism to build roads after the country was formed.

PPP and health care in the USA is limited by several factors. First, the

Second, there is very little coordination in the US health-care system. Rather, regulatory power is fragmented across local, subnational and national levels. The responsibility for providing public health is divided among 50 states, five territories and 90,000 local governments (United States Census Bureau, 2020). The laws and regulations that govern PPP usage are largely the responsibility of the states, with some input from the national government. But with states as the regulatory body, there is substantial variation in laws and regulations that limit the ability of PPP to be used everywhere.

PPPs have grown in popularity in the USA over the past 30 years, when California enacted the first piece of legislation governing these organizational arrangements. The trend in PPP in the health care, as well as other areas, has been predominantly driven by cost crisis in the USA, as well as quality concerns. Public sector health-care providers are challenged by the increasing costs of care, the patient populations they serve, which are more likely to be low-income and uninsured (Fraze et al., 2006), operating older health-care facilities (King et al., 2018) and diminished financial support from their state governments (Krein et al., 2010).

\section{Findings and discussion}

Case study $A$

The case study A is a PPP contracted in a central Italian region for the provision of four hospitals and its relative maintenance services. All hospitals have been completed in 2006, and since then, there has not been any litigation between the two parts. The private contractor is the concessionaire and is a joint-stock company, whereas the public contractor, 
IJOA
29,6

1474

named provider, is the regional authority itself. The asset and capital manager acted out as project manager during the realization of the structure and throughout the whole construction phase. The role of intermediary has been fulfilled by the same project manager, who was technically not part of the PPP contract.

\section{Case study B}

The case study B is a PPP that was contracted in the USA between a public health-care organization (provider) and a private entity (concessionaire) to manage clinical operations to ensure long-term financial stability, to address the challenges of hospital consolidation in the region, and to enhance funding for the organizations academic and research mission. The hospital has more than 200 hospital beds, several outpatient clinics and a medical group of providers. The PPP arrangement began in earnest in 2017, though financial strain over the prior years had led to public officials encouraging hospital officials to pursue private financial backing. The PPP was arranged by a global financial consulting firm with expertise in facilitating and coordinating the process, though they were not part of the PPP contract.

The major findings emerging from this work over the two said cases are schematically represented in the Tables 2,3 and 4 .

\section{Issue 1: auditing and performance measurement}

The first issue analyzed over the two selected organizations consists in the auditing and performance measurement activity. The assessment of contracts found that, although they rely on the same framework, the two PPPs use a different approach for auditing and performance measurement (Table 2).

Following the framework analyzed by Robinson and Scott (2009), the first sub-issue taken into account is the existence and the function of a monitoring system. Case study B identifies in the contract a detailed scheme of performance monitoring, institutionalizing a

\begin{tabular}{|c|c|c|}
\hline & Key Issue 1 - Auditing and performan & ce measurement \\
\hline & Case study A (ITALY) & Case study B (USA) \\
\hline $\begin{array}{l}\text { Monitoring } \\
\text { regime }\end{array}$ & $\begin{array}{l}\text { Contractors' performance is subject to } \\
\text { periodical audit by the identified audit } \\
\text { authority. The contract specifies a self- } \\
\text { monitoring procedure to be followed, but } \\
\text { there is no specification on the methodology } \\
\text { of monitoring to be adopted by the } \\
\text { contractors }\end{array}$ & $\begin{array}{l}\text { Contractors are both subject to } \\
\text { continuous audit, one every month. A } \\
\text { third entity is required to undertake this } \\
\text { function and a monitoring system is well } \\
\text { detailed }\end{array}$ \\
\hline $\begin{array}{l}\text { Customer } \\
\text { satisfaction }\end{array}$ & $\begin{array}{l}\text { There is no reference to the customer } \\
\text { satisfaction in the contract, and therefore, it is } \\
\text { not able to influence deductions }\end{array}$ & $\begin{array}{l}\text { Customer satisfaction accounts in the } \\
\text { determination of deductions }\end{array}$ \\
\hline $\begin{array}{l}\text { Performance } \\
\text { reporting }\end{array}$ & $\begin{array}{l}\text { The local authority (regional government) } \\
\text { requires a periodical performance report, with } \\
\text { potential deductions for performance } \\
\text { calculated according to a specific formula }\end{array}$ & $\begin{array}{l}\text { No performance reports are required by } \\
\text { the governmental authority involved in } \\
\text { the PPP contracts }\end{array}$ \\
\hline Fault reporting & $\begin{array}{l}\text { The contract does not require a staff } \\
\text { reporting procedure. No location is available } \\
\text { for this issue }\end{array}$ & $\begin{array}{l}\text { A self-reporting procedure is applied, } \\
\text { promoting culture of change }\end{array}$ \\
\hline
\end{tabular}

\section{Table 2.}

Key aspects on auditing and performance measurement

Source: Our elaboration 
Key Issue 2 - determination of compensation

\section{Case study A (ITALY)}

Performance scoring system and deduction

Performance compensation is weighted according to the weight attributed to each area of interest defined in the contract with a provided formula. This means that each area has weighted coefficients for the determination of the remuneration

Function of payment mechanism

Payments, although can very according to different specification in the contract, are not very flexible and accounts for less than $20 \%$. Payments are made every six months

Staff management and The staff management issue is not addressed compensation
Case study B (USA)

The performance deduction in the determination of compensation accounts for more than $50 \%$ of the entire amount defined in the contract. Every area has a strong specification on the amount of deductions for any possible emerging issue. but there are no coefficient used for the calculation, as every single area is well detailed and specified The payment scheme is not really clear and is not included in the contract

According to the contract, a frequent change of staff is possible and can make strong work relationships. Furthermore, the component of staff compensation is very sensible to the entity's performance

No specific formula is used
Complexity issues

1475

Table 3.

Key aspects on determination of compensation

specific independent body in charge of this task. Furthermore, this body is due to provide a monthly report touching every aspect of the relation (financial, organizational and output and outcome assessment) and to limit as much as possible subjectivity in the analysis, requiring the report has to be blind reviewed during each assessment. While in case study A, the contract does not specify the methodology to be adopted and does not institutionalize an independent body to take charge of this aspect, leading to possible conflict of interests.

Customer satisfaction is the second aspect taken into account. The case study A does not provide any specification in the contract, whereas case study B uses it to base determination of deductions in the contract.

As for the third element of this issue, consisting in the performance reporting, the case study B does not require any specific transparent output, whereas case study A is required by public authorities to justify its performance each year. Furthermore, the public authority specifies the formula to use in this determination.

The last aspect taken into analysis consisted in the presence of a fault reporting procedure that is found to be present only in case study B with the specific purpose, according to secondary sources viewed, to promote the culture of change in the organizations.

\section{Issue 2: determination of compensation}

The second issue retrieved from the analysis of Robinson and Scott (2009) concerns the determination of compensation (Table 3). This aspect is strongly related to the risk taken by the two entities, which is deeper analyzed in the next paragraph (Table 4). In case study A, 
IJOA

29,6

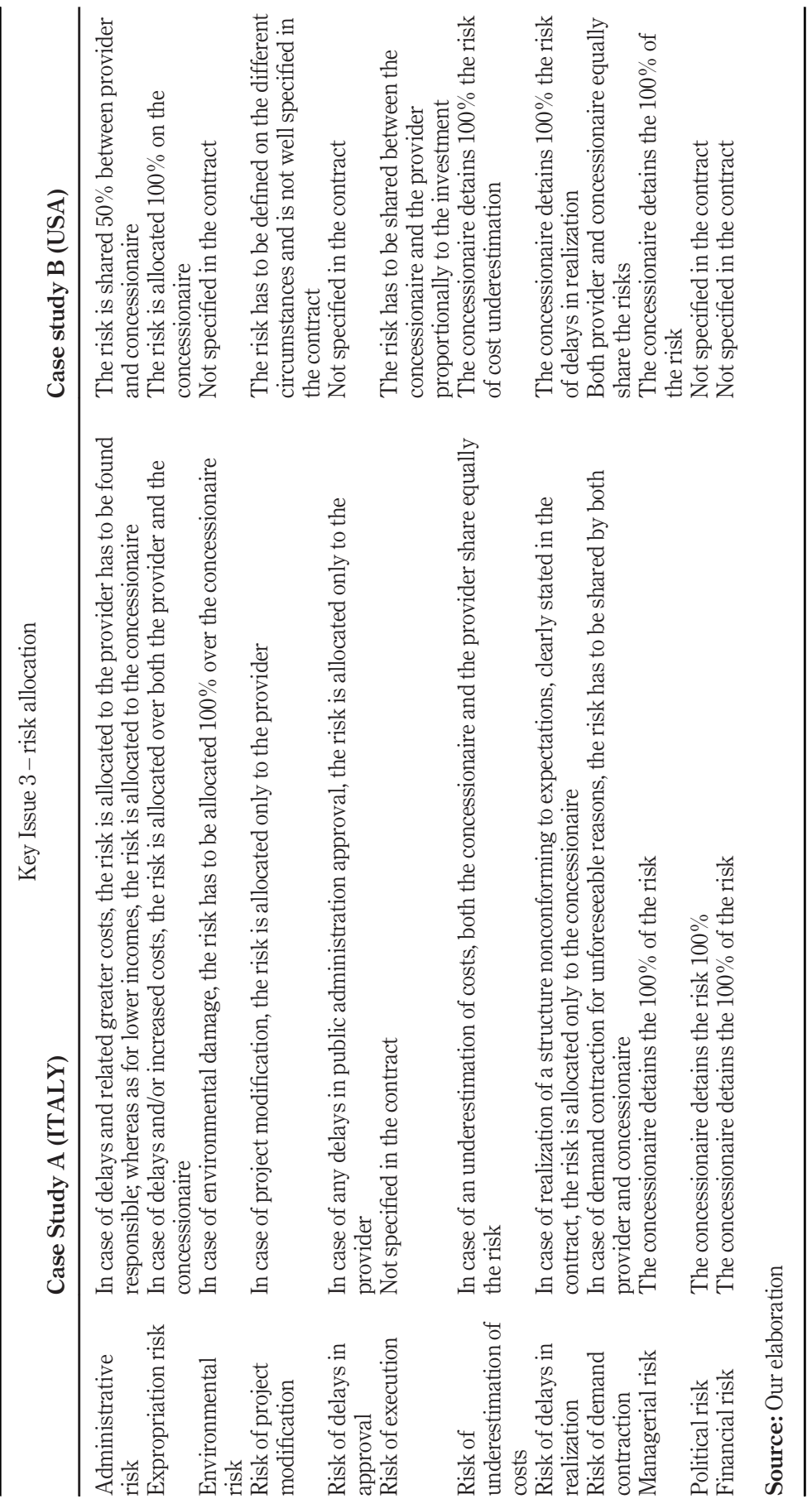

Table 4.

Key aspects on risk allocation 
the performance compensation is weighted to each area defined in the contract. Each area is defined in the contract, and the same contract provides the formula to calculate the compensation as well as any possible adaptation in price changing. However, no performance deduction is directly specified in the document. Case study $\mathrm{B}$ does not report any specific remuneration formula. One area where case study B clearly delineates compensation is in addressing staff and management pay. Case study A does not include any specific determination of pay changes for staff and management in their contracting.

\section{Issue 3: risk management}

To analyse risk management, we compare PPP contracting to a matrix developed by the Ministry of Economy of Italy (2017). Twelve major types of risks are defined in the matrix. We find that PPP contracts differ in several respects in how they account for and manage their risks. Case study A generally provides a more robust framework in their contracting to manage and allocate risk. For example, if delays are incurred during the PPP, case study A delineates how the financial risk is divided between the provider and the concessionaire. In only one category of risk did case study A not specifically outline the contractual obligations of the parties involved in a PPP - that of risk of execution. In the case of that risk, case study $\mathrm{B}$ did include contracting language proportionally sharing the risk between the provider and the concessionaire.

Table 4 defines to which entity the risk is allocated to. Furthermore, Table 5 describes the type of risks selected.

\section{Conclusions}

The use of PPP is not a recent phenomenon. In both Italy and the USA, it has long been used as a policy tool. In both settings, there has been consistent growth in the use of PPP over the past 20 years (Torchia and Calabrò, 2018).

Yet, in the specific case of health care, our cases analysis shows the divergences between Italy and the USA in the use of PPP. Indeed, in Italy, where the public sector is more pronounced and prevalent in the health-care setting, our case confirms find a more substantial and robust use of contracting in PPPs; although because of its complexity, the saturation of the market reached and the issues to which this type of agreement is subject to, it has experienced a general decrease in 2010s (Soecipto and Verhoest, 2018).

The different historical, social and economic contexts between Italy and the USA has led to the different use of PPPs and shaped the contracting of these relationships. Yet, in both cases, even with the different factors that have shaped their use and history, PPPs represent a challenge for the private sector as well as an opportunity for the public sector to modernize the provision of care (Robinson and Scott, 2009).

One of the core challenges associated with adopting PPPs is the innate complexity with the arrangements. It is difficult to standardize across different scenarios and arrangements. Yet, there are three themes that have emerged from our case studies and seem to confirm the general trend identified by scholars. First, the case study B is more oriented to the culture of change rather than Case study A, sustaining theory according to which the US context may affect organizations to be more prone to the change rather than an organization located in Italy (Hofstede et al., 2005; Fey and Denison, 2003; Brewster, 2004). This emerged from the fact that the American contract analyzed is more flexible and opened to possible drift in the management of the relation. A wide literature has emerged on the topic of organizations orientation to change, and indeed the conclusions do not differ much when it comes to formulating judgments on geographical predisposition to change. American organizations, according to several authors (Ongaro, 2009; Goodstein and Burke, 1991), tend to be more flexible and oriented to a rapid change in 


\section{Classification of risks}

$\begin{array}{lll}\text { Type of risk Risk definition } & \text { Potential consequences }\end{array}$

Administrative risk Risk related to delays or failure in obtaining necessary authorization by public or private entities to start the project

Expropriation risk Risk related to delays or failure in expropriation procedures and/or increase of costs for necessary expropriations

Environmental risk

Non-foreseeable risks related to contamination of the territory

Risk of project modification

Risk of delays in approval

Risk of execution

Risk of underestimation of costs

Risk of delays in realization Risk of demand contraction Managerial risk

Political risk

Table 5.

Classification of risks contractors on the original project Risk related to delays in the approval of the project by public or private entities project nonconforming to the original plan agreed by the two parties the contract is signed

Risk related to delays in realization by the concessionaire

Risk related to the concentration of the demand of services with established tariffs Risk related to potential increase of management costs, risk related to the provision of services nonconforming to standards, risk of failure in the provision of services affecting the project; risk of change in to the project
Delays, increasing of costs, decreasing of revenue

Delays, increasing of costs

Delays, increasing of costs

Delays, increasing of costs

Delays, increasing of costs, decreasing of revenue, redress application, contract resolution Delays, increasing of costs, decreasing of revenue, redress application, contract resolution

Risk related to underestimation of costs when

Delays, increasing of costs,

decreasing of revenue

Delays, increasing of costs, potential resolution of the contract

Decreasing of revenue

Disservices, increasing of costs, decreasing of revenue, decreasing of contractors' compensation, redress application, resolution of the contract

Risk related to potential change in regulations political leadership undermining commitment

Financial risk Risk related to accessing funds
Delays, increasing of costs, decreasing of revenue

Delays, increasing of costs, decreasing of revenue, contract resolution

organizational culture rather than European counterparts. In these cases, we found the same trend: a clear orientation to the management of staff and a general encouragement of researching different positions of the staff within the contractual agreement made by the two public and private entities seem to reflect this trend.

Second, the public contractor, namely the provider, detains more risk in the Case study A, rather than Case study B. This implies that Italian public organizations share more risks with private counterparts rather than American public organizations. According to Decressin (2002), countries that have equal access to public services, namely health, are thus subject to an increased risk.

It is also true that the risk in complex relations such as PPPs should be handled on a case-bycase basis (Bing et al., 2005), and several other authors reached the opposite conclusion, stating that the public party in Italy is the harassed and weak part of the contract (Carbonara and Pellegrino, 2014). Indeed, this has historical reasons. PPPs in Italy represented a new way of accessing funds for the public sector in early 2000s, which have suffered from a general decrease of resources over time (Torchia and Calabrò, 2015). PPPs were seen as a possible solution (Carnis and Yuliawati, 
2013), but in that circumstances, the public counterpart had less contractual power and has been subject to harder conditions (Vecchi et al., 2020). The analyzed case does not confirm this trend. Further studies are needed to better understand this phenomenon.

Finally, there is way more flexibility in the deductibility and compensation determination in the American agreement. Cases seem to confirm the evidence and suggest that the public sector pursue deductions in the "spirit of partnership" (Robinson and Scott, 2009) in exchange for less accountability, and therefore less risk, within the contract. The creation of a partnership with mutually agreed objectives is an essential aspect to be researched to minimize opportunistic behaviors associated with incomplete contractual fulfillment required. The complexity of this type of relation, which well represents the principal-agent theory dilemma, needs to be regulated and defined in the contract, providing a higher grade of flexibility. This issue seems to be addressed more in the American organization analyzed rather than the Italian organization, as flexibility in risk sharing and determination of compensation is indeed greater.

Therefore, PPP despite representing an innovative alternative to privatization surely has to deal with a certain number of issues. This may undermine the effectiveness of the common purposes, exposing PPPs to unforeseeable risks. This paper aims to detect what might be the most recurrent issue to be faced in PPPs agreement and how two independent organizations face these issues in two completely different contexts. We indeed find that differences in the contexts strongly affect also the type of relations as well as the way the involved entities face the problematics. Every organization has its own path dependence.

\section{Limitations}

The results we have presented here should be considered in several limitations. First, we have selected case study countries that vary substantially across several key dimensions. Yet, there are a variety of different dimensions we could have analyzed in our selection. Second, we have analyzed only primary document consisting in contracts and published agreements related to the arrangement and contracting of PPPs. In-depth interviews may be a future challenge to understand the promise and peril of PPPs.

Understanding the problems that PPPs face and the current mechanisms in place to account for them goes beyond just an academic exercise. Rather, a suboptimal PPP arrangement can endanger patient lives and the financial stability of governments and health-care organizations. Our analysis is merely the first attempt to understand how healthcare organizations structure their PPP arrangements. There is a rich area of future research to better quantify and understand PPP arrangement in health-care settings.

\section{References}

An, X., Li, H., Wang, L., Wang, Z., Ding, J. and Cao, Y. (2018), “Compensation mechanism for urban water environment treatment PPP project in China”, Journal of Cleaner Production, Vol. 201, pp. 246-253.

Bing, L., Akintoye, A., Edwards, P.J. and Hardcastle, C. (2005), "The allocation of risk in PPP/PFI construction projects in the UK", International Journal of Project Management, Vol. 23 No. 1, pp. 25-35.

Bovaird, T. (2007), "Beyond engagement and participation: user and community coproduction of public services", Public Administration Review, Vol. 67 No. 5, pp. 846-860.

Brekke, K.R. and Sørgard, L. (2007), "Public versus private health care in a national health service", Health Economics, Vol. 16 No. 6, pp. 579-601.

Brewster, C. (2004), "European perspectives on human resource management", Human Resource Management Review, Vol. 14 No. 4, pp. 365-382.

Brinkerhoff, D.W. and Brinkerhoff, J.M. (2011), "Public-private partnerships: Perspectives on purposes, publicness, and good governance", Public Administration and Development, Vol. 31 No. 1, pp. 2-14. 
IJOA

29,6

Brown, D. (2020), "A review of the PubMed PICO tool: using evidence-based practice in health education”, Health Promotion Practice, Vol. 21 No. 4, pp. 496-498.

Carbonara, N. and Pellegrino, R. (2014), "PPP for public infrastructure in Italy: opportunity and challenges", Managerial Finance, Vol. 40 No. 11.

Carbonara, N., Costantino, N., Gunnigan, L. and Pellegrino, R. (2015), "Risk management in motorway PPP projects: empirical-based guidelines", Transport Reviews, Vol. 35 No. 2, pp. 162-182.

Carnis, L. and Yuliawati, E. (2013), "Nusantara: between sky and earth could the PPP be the solution for Indonesian airport infrastructures?", Case Studies on Transport Policy, Vol. 1 Nos 1/2, pp. 18-26.

Decressin, J. (2002), "Regional income redistribution and risk sharing: how does Italy compare in Europe?", Journal of Public Economics, Vol. 86 No. 2, pp. 287-306.

Del Vecchio, M., Fenech, L. and Prenestini, A. (2015), "Private health care expenditure and quality in beveridge systems: Cross-regional differences in the Italian NHS”, Health Policy, Vol. 119 No. 3, pp. 356-366.

Du Toit, J. (2003), "PPP insights in South Africa", World Hospitals and Health Services: The Official Journal of the International Hospital Federation, Vol. 39 No. 1, p. 2.

Duggan, M., Gruber, J. and Vabson, B. (2015), The Efficiency Consequences of Health Care Privatization: evidence from Medicare Advantage Exits (No. w21650), National Bureau of Economic Research.

Falco, R.D. (2019), “Access to care and the global financial crisis in Italy: a human rights perspective”, $e$ Cadernos CES, No. 31.

Fanelli, S., Lanza, G., Francesconi, A. and Zangrandi, A. (2020), "Facing the pandemic: the Italian experience from health management experts' perspective", The American Review of Public Administration, Vol. 50 Nos 6/7, pp. 753-761.

Fanelli, S., Salvatore, F.P., De Pascale, G. and Faccilongo, N. (2020), "Insights for the future of health system partnerships in low-and middle-income countries: a systematic literature review", $B M C$ Health Services Research, Vol. 20 No. 1, pp. 1-13.

Feagin, J. R., Orum, A. M. and Sjoberg, G. (Eds) (1991), A Case for the Case Study, UNC Press Books.

Ferrario, C. and Zanardi, A. (2011), "Fiscal decentralization in the Italian NHS: what happens to interregional redistribution?", Health Policy, Vol. 100 No. 1, pp. 71-80.

Finlombarda (2011), IX Osservatorio Finlombarda Sul Project Finance in Sanità, Maggioli Editore, Italy.

Fraze, T. Elixhauser, A. Holmquist, L. and Johann, J. (2006), "Public hospitals in the United States, 2008: Statistical brief\# 95 ".

Garen, J.E. (1994), "Executive compensation and principal-agent theory”, Journal of Political Economy, Vol. 102 No. 6, pp. 1175-1199.

Goh, C.Y. and Marimuthu, M. (2016), "The path towards healthcare sustainability: the role of organisational commitment", Procedia - Social and Behavioral Sciences, Vol. 224, pp. 587-592.

Golinelli, D., Toscano, F., Bucci, A., Lenzi, J., Fantini, M.P., Nante, N. and Messina, G. (2017), "Health expenditure and all-cause mortality in the 'galaxy'of Italian regional healthcare systems: a 15year panel data analysis", Applied Health Economics and Health Policy, Vol. 15 No. 6, pp. 773-783.

Goodstein, L.D. and Burke, W.W. (1991), "Creating successful organization change”, Organizational Dynamics, Vol. 19 No. 4, pp. 5-17.

Grimsey, D. and Lewis, M.K. (2004), "The governance of contractual relationships in public-private partnerships", Journal of Corporate Citizenship, Vol. 2004 No. 15, pp. 91-109.

Herr, A., Schmitz, H. and Augurzky, B. (2011), "Profit efficiency and ownership of German hospitals", Health Economics, Vol. 20 No. 6, pp. 660-674.

Hodge, G.A. and Greve, C. (2017), "On public-private partnership performance: a contemporary review", Public Works Management and Policy, Vol. 22 No. 1, pp. 55-78.

Hofstede, G., Hofstede, G.J. and Minkov, M. (2005), Cultures and Organizations: Software of the Mind, (Vol. 2). New York, NY: Mcgraw-hill. 
Hullegie, P. and Klein, T.J. (2010), "The effect of private health insurance on medical care utilization and self-assessed health in Germany", Health Economics, Vol. 19 No. 9, pp. 1048-1062.

Jefferies, M., Gameson, R.O.D. and Rowlinson, S. (2002), "Critical success factors of the BOOT procurement system: reflections from the stadium Australia case study", Engineering, Construction and Architectural Management, Vol. 9 No. 4, pp. 352-361.

Ke, Y., Wang, S., Chan, A.P. and Cheung, E. (2011), "Understanding the risks in china's PPP projects: ranking of their probability and consequence", Engineering, Construction and Architectural Management, Vol. 18 No. 5.

King, D.D. Beebe, C. Suchomel, J. Bardwell, P. Della Donna, V. and Walt, L. (2018), "State of U.S. Health care facility infrastructure",

Kivleniece, I. and Quelin, B.V. (2012), "Creating and capturing value in public-private ties: a private actor's perspective", Academy of Management Review, Vol. 37 No. 2, pp. 272-299.

Krein, S.L., Damschroder, L.J., Kowalski, C.P., Forman, J., Hofer, T.P. and Saint, S. (2010), "The influence of organizational context on quality improvement and patient safety efforts in infection prevention: a multi-center qualitative study", Social Science and Medicine, Vol. 71 No. 9, pp. 1692-1701.

Mehl, G., Vasudevan, L., Gonsalves, L., Berg, M., Seimon, T., Temmerman, M. and Labrique, A. (2014), "Harnessing mHealth in low-resources settings to overcome health system constraints and achieve universal access to healthcare", Behavioral Healthcare and Technology: Using ScienceBased Innovations to Transform Practice, Vol. 239.

Meleddu, M. Pulina, M. and Scuderi, R. (2019), "Public and private healthcare services: What drives the choice?”, Socio-Economic Planning Sciences, Vol. 70, p. 100739.

Mishra, D., Gunasekaran, A., Papadopoulos, T. and Hazen, B. (2017), "Green supply chain performance measures: a review and bibliometric analysis", Sustainable Production and Consumption, Vol. 10, pp. 85-99.

Neri, S. (2019), "Economic crisis, decentralisation and health inequalities: the case of Italy", In Universal Health Coverage, IntechOpen, Rome.

Ongaro, E. (2009), Public Management Reform and Modernization: Trajectories of Administrative Change in Italy, France, Greece, Portugal and Spain, Edward Elgar Publishing. Chettelman.

Osbourne, S. (2000), Public-Private Partnerships for Public Services: An International Perspective, Routledge, London.

Propper, C. (2000), "The demand for private health care in the UK", Journal of Health Economics, Vol. 19 No. 6, pp. 855-876.

Robinson, H.S. and Scott, J. (2009), "Service delivery and performance monitoring in PFI/PPP projects", Construction Management and Economics, Vol. 27 No. 2, pp. 181-197.

Shrestha, A., Chan, T.K., Aibinu, A.A. and Chen, C. (2017), "Efficient risk transfer in PPP wastewater treatment projects", Utilities Policy, Vol. 48, pp. 132-140.

Shrestha, A., Tamošaitienė, J., Martek, I., Hosseini, M.R. and Edwards, D.J. (2019), “A principal-agent theory perspective on PPP risk allocation”, Sustainability, Vol. 11 No. 22, p. 6455.

Signorelli, C., Odone, A., Oradini-Alacreu, A. and Pelissero, G. (2020), "Universal health coverage in Italy: lights and shades of the Italian national health service which celebrated its 40th anniversary", Health Policy, Vol. 124 No. 1, pp. 69-74.

Signorelli, C., Odone, A., Gozzini, A., Petrelli, F., Tirani, M., Zangrandi, A., ... Florindo, N. (2017), “The missed constitutional reform and its possible impact on the sustainability of the Italian national health service”, Acta Bio-Medica: Atenei Parmensis, Vol. 88 No. 1, pp. 91-94.

Soecipto, R.M. and Verhoest, K. (2018), "Contract stability in European road infrastructure PPPs: How does governmental PPP support contribute to preventing contract renegotiation?", Public Management Review, Vol. 20 No. 8, pp. 1145-1164.

Tellis, W. (1997), "Introduction to case study”, The Qualitative Report, Vol. 269. 
IJOA
29,6

1482

Thomson, S. and Mossialos, E. (2006), “Choice of public or private health insurance: learning from the experience of Germany and The Netherlands", Journal of European Social Policy, Vol. 16 No. 4, pp. 315-327.

Tiemann, O. and Schreyögg, J. (2009), "Effects of ownership on hospital efficiency in Germany", Business Research, Vol. 2 No. 2, pp. 115-145.

Torchia, M. and Calabrò, A. (2018), "Increasing the governance standards of public-private partnerships in healthcare", Public Organization Review, Vol. 18 No. 1, pp. 93-110.

United States Census Bureau (2020), Census of Governments, Washington, DC.

Vecchi, V., Casalini, F., Cusumano, N. and Leone, V.M. (2020), "PPP in health care - trending toward a light model: evidence from Italy", Public Works Management and Policy, Vol. 25 No. 3, pp. 244-258.

Villani, E., Greco, L. and Phillips, N. (2017), "Understanding value creation in public-private partnerships: a comparative case study",Journal of Management Studies, Vol. 54 No. 6, pp. 876-905.

World Health Organization (2000), The World Health Report 2000: health Systems: improving Performance, World Health Organization.

World Health Organization (2019), WHO Global Report on Traditional and Complementary Medicine 2019, World Health Organization.

$\mathrm{Xu}$, Y., Chan, A.P. and Yeung, J.F. (2010), "Developing a fuzzy risk allocation model for PPP projects in China", Journal of Construction Engineering and Management, Vol. 136 No. 8, pp. 894-903.

\section{Further reading}

American Hospital Association (2020), "Fast facts on US Hospitals, 2020",

Fey, C.F. and Denison, D.R. (2003), "Organizational culture and effectiveness: can American theory be applied in Russia?”, Organization Science, Vol. 14 No. 6, pp. 686-706.

Kilgour, E., Kosny, A., McKenzie, D. and Collie, A. (2015), "Healing or harming? Healthcare provider interactions with injured workers and insurers in workers' compensation systems", Journal of Occupational Rehabilitation, Vol. 25 No. 1, pp. 220-239.

Ministry of Economy, Italy (2017), Una Proposta di Rilancio Del Partnenariato Pubblico Privato, Rome.

Partnerships, U.K. (2006), Report on Operational PPP, PFI Projects. London.

Torchia, M., Calabrò, A. and Morner, M. (2015), "Public-private partnerships in the health care sector: a systematic review of the literature", Public Management Review, Vol. 17 No. 2, pp. 236-261.

\section{About the authors}

Lorenzo Pratici is PhD attendant at the Department of Economics and Management at the University of Parma, Italy. His main interests among research includes, but are not limited to, public administration, public management, nonprofit organizations with a specific focus on health-care organizations. His works concern management topics as well as accounting among public-owned firms (hospitals, schools, universities, local administrations, penitentiary institutions, etc.). Lorenzo Pratici is the corresponding author and can be contacted at: lorenzo.pratici@unipr.it

Phillip McMinn Singer is Assistant Professor at the University of Utah in the Department of Political Science, as well as Adjunct Assistant Professor in the Department of Population Health Sciences. He received his $\mathrm{PhD}$ and Masters in Health Services Administration from the University of Michigan. His research focuses on the health-care management and policy, with a particular emphasis on the nonprofit and private sectors of the health-care industry, as well as an emphasis on public policy and business. He published in the New England Journal of Medicine, JAMA, BMJ, the American Journal of Public Health, and other high-impact journals.

For instructions on how to order reprints of this article, please visit our website:

www.emeraldgrouppublishing.com/licensing/reprints.htm

Or contact us for further details: permissions@emeraldinsight.com 